\title{
Flammability of urban ornamental species for use in green firebreaks
}

\author{
Fernanda Moura Fonseca Lucas ${ }^{1 *}$, Bruna Kovalsyki ${ }^{l}$, Rudolfo de Cerqueira Jacobs ${ }^{l}$, \\ Alexandre França Tetto ${ }^{l}$, Antonio Carlos Batista ${ }^{l}$
}

\author{
${ }^{1}$ Federal University of Paraná (UFPR), Curitiba, Brazil \\ * e-mail: fernanda.fonseca@hotmail.com
}

\begin{abstract}
Wildfire promotes disruption to ecosystems, and one of the preventive measures taken to reduce their effects is green firebreak. This measure consists of plantations along strips and in different strata with low-flammability species, which act as a physical barrier reducing or preventing the passage of fire. The characterization of species that may make up these green firebreak is basic and essential studies for the adequacy of preventive measures, capable of meeting other sectors such as the landscaping. Therefore, this work aimed to evaluate the flammability of two urban ornamental species: Eugenia uniflora L. and Persea gratissima Gaertn F. for use in green firebreaks. The experiment was conducted at the Protection Forestry Laboratory of the Federal University of Paraná, Brazil. Flammability was tested by controlled burning in an epiradiator, with a temperature ranging from 320 to $390^{\circ} \mathrm{C}$, using 1 gram of freshly collected mature thin material $(<0.7$ centimeters in diameter). Fifty repetitions per species were performed, being: ignition time, combustion duration, flame height, and ignition frequency. From the mean of these variables, the flammability and intensity values were obtained for both species. Also, the green mass of a fraction of the plant material was determined and, after remaining in the greenhouse for 48 hours at $75^{\circ} \mathrm{C}$, the dry mass estimated for getting moisture content. According to the tests performed, it was found E. uniflora showed the highest ignition frequency (37) compared to P. gratissima (28). This may be correlated with a lower moisture content found in the fuel material of the first species (87.10\%) compared to the second (150.91\%). Both presented high combustion intensity, with an average flame length greater than 12 centimeters. However, based on the frequency and timing of ignition (average 28 seconds for $E$. uniflora and 35.4 seconds for $P$. gratissima), both were considered weakly flammable, thus presenting, in addition to ornamental quality, potential for use in green firebreaks.
\end{abstract}

Keywords: protection forestry; wildfire; green barriers. 